\title{
Prognosis of lower respiratory tract infected patients with virus detected in bronchial alveolar lavage fluid: a retrospective observational study
}

\section{Yuan Zhang}

Shanghai General Hospital, Shanghai Jiao Tong University School of Medicine

\section{Qiuping Huang}

Shanghai General Hospital, Shanghai Jiao Tong University School of Medicine

\section{Zhigang Zhou}

Shanghai General Hospital, Shanghai Jiao Tong University School of Medicine

\section{Yun Xie}

Shanghai General Hospital, Shanghai Jiao Tong University School of Medicine

\section{Xianchen Li}

Clinical Research Center, Shanghai General Hospital, Shanghai Jiao Tong University School of Medicine

\section{Wei Jin}

Shanghai General Hospital, Shanghai Jiao Tong University School of Medicine

\section{Ruilan Wang ( $\nabla$ wangyusun@hotmail.com )}

Shanghai General Hospital of Nanjing Medical University

\section{Research article}

Keywords: metagenomic sequencing, virus, bronchial lavage fluid, prognosis

Posted Date: June 7th, 2020

DOl: https://doi.org/10.21203/rs.3.rs-27799/v1

License: (c) (1) This work is licensed under a Creative Commons Attribution 4.0 International License. Read Full License 


\section{Abstract}

Background and Objectives The influence of virus detected in BALF is still debating. This study aimed to compare the prognosis of lower respiratory tract infected patients with virus detected in bronchial alveolar lavage fluid (BALF) and patients with virus undetected by using metagenomic next-generation sequencing technology.

Methods This was a retrospective cohort study. 53 patients with lower respiratory tract infection were enrolled. BALF samples were collected from each patient and sent to perform mNGS pathogenic test in the study. According to the results of mNGS test, patients were divided into virus-detected group and virus-undetected group. In the meanwhile, patients' clinical information, medical history, disease severity scores, parameters of organ function at the day of ICU admission, prognosis, hospital length of stay, ICU length of stay and needs for medical support were also collected.

Results 39.6 percent $(21 / 53)$ of the BALF samples were virus nucleic acid positive. Mortality rate, tracheotomy rate, mechanical ventilation supporting time, blood transfusion rate were significantly higher in virus-detected group than that in virus-undetected group. Virus-detected was closely related to hospital and ICU survival time.

Conclusions Patients with virus detected in BALF were prone to a poorer prognosis. The detection of virus was a high-risk factor of death for LRTI patients. Virus-detected patients required more medical resources.

\section{Introduction}

Community acquired lower respiratory tract infection (LRTI) is the most common reason of requiring mechanical ventilation support among various kinds of cases admitted to an Intensive Care Unit (ICU ). In the past, bacterial infection was considered to be the leading cause of community acquired pneumonia ( CAP ), and Streptococcus Pneumoniae accounted nearly half of the criminal pathogen. However, since the outbreak of Influenza A ( H1N1) in 2009, there was an increasing number of viral pneumonia cases admitted to ICU[1]. Studies on American adult or pediatric CAP patients who required hospitalization indicated that respiratory viral infection accounted for the largest proportion[2, 3]. A prospective study on the etiology of adult LRTI in an European primary hospital founded that bacterial infection accounted for one fifth of the total while viral infection accounted for nearly half[4].

Isolation and identification of the virus is the "gold standard" for virus detection, however, complicated procedure and long time for cultivation limit the clinical application. Molecular diagnostic technologies such as Polymerase Chain Reaction (PCR) can rapidly and directly detect the pathogens from a clinical sample, which improving the diagnostic efficiency greatly. But the shortcoming is its relatively narrow pathogenic detection range and requiring to predefine the possible pathogen according to the clinical manifestation in priority [5]. Only one pathogen or a limited array of pathogens can be check once a time. 
Metagenomic next-generation sequencing (mNGS) is an efficient molecular diagnostic tool used in various clinical setting, from lab to clinics. Based on next-generation sequencing technology, it can detect genetic composition of all the microorganism in a sample, sequencing billions of DNA or RNA fragments simultaneously. Although it is not as fast as PCR for pathogen detection, it can comprehensively detect all the pathogenic nucleic acid in a sample or even explore the microbial community and human host response through transcriptome analysis at the same time[6].

Bronchial alveolar lavage fluid (BALF) is a commonly used sample type of mNGS. In the clinical practice, we have noticed that virus nucleic acid fragments are often detected positive in the BALF when sequenced. Whether virus detected in BALF mean something is still controversial among researchers.

Vergera et al[7] founded that cytomegalovirus (CMV) detected positive in BALF from critically ill patients was associated with longer hospital length of stay (HLOS ) and higher mortality rate. Meanwhile, another study on pediatric patients whose CMV DNA was detected from BALF concluded that the CMV was commonly found in BALF, which didn't mean acute dominant CMV infection and wouldn't be regarded as the first primary diagnose[8].

The relationship between virus detected in BALF and clinical significance is still debating. This study intended to discuss the influence of virus detected in BALF on patients' prognosis and summarize some relevant clinical experience.

\section{Materials And Methods \\ Study design}

This was a retrospective observational cohort study. we enrolled consecutive patients with LRTI admitted to or transferred to the ICU in Shanghai General Hospital, Shanghai Jiao Tong University School of Medicine from Nov 2017 to Nov 2019. A sample of BALF from each patient was collected to perform metagenomic sequencing.

According to sequencing results, patients were divided into virus-detected group ( Virus nucleic acid were detect positive in BALF, no matter which virus was detected ) and virus-undetected group. Patient demographic characteristics, clinical parameters, prognosis, length of stay and utilization of related medical resources were also recorded by medical records.

The human research ethic committee of Shanghai General Hospital approved this retrospective observational clinical study. Due to the retrospective nature of the study, informed consent was waived.

\section{Inclusion criteria}

We screened all consecutive patients with LRTI admitted to or transferred to the ICU from Nov 2017 to Nov 2019. LRTI mainly included acute exacerbation of chronic obstructive pulmonary diseases, community-acquired pneumonia and acute bronchitis. These diagnoses were made based on clinical 
characteristics, test reports and chest radiography. The inclusion criteria were (1) age 18 years or above, (2) patient was clinically diagnosed as lower respiratory tract infection (3) BALF sample had been obtained for mNGS test.

\section{Exclusion criteria}

Patient was excluded when (1) younger than 18, (2) hadn't been discharged yet within the research time, (3) the cases was impossible to do accurate statistics due to data losing.

\section{Data collection}

Routine blood sample were drawed at the time of ICU admission. Demographic information (age, gender, medical history, immune status ), disease severity scores (APACHE II, SOFA ), relevant infection variables [ leukocytes ( WBC ), C-reactive protein ( CRP ), interleukin-6 ( IL-6 ), procalcitonin ( PCT ), B-(1,3)-D glucan ( $\mathrm{G}$ test $)$ ], immune indices $\left(\mathrm{CD}_{4} \%, \mathrm{CD}_{8} \%, \mathrm{CD}_{4} / \mathrm{CD}_{8}\right.$ ratio), organ function parameters [ alanine transaminase (ALT), albumin ( ALB ), total bilirubin ( TB ), serum creatinine ( $\mathrm{Scr}$ ), prothrombin time (PT ), platelet ( PLT ), troponin I ( $\mathrm{CTnl}$ ) ], outcome and measured parameters [ mortality rate, hospital length of stay (HLOS), ICU length of stay (ICULOS), mechanical ventilation (MV) supporting time, tracheotomy rate, hemodialysis rate, blood transfusion rate ] were collected respectively by medical records.

Due to traditional habits, patients in our country would not be followed up regularly. The study lacked clinical data related to patients' follow-up information.

Mortality means patients died in ICU, or was dying when the client required being discharged.

\section{Metagenomic next-generation sequencing}

BALF samples were obtained by an operator who had at least two years full-time working experience,following standardized operational flow. $96.2 \%$ participants were intubated. The specimen was then sent to a qualified pathogenic microorganism detection center for DNA sequencing. After the procedure of nucleic acid extraction, library preparation, DNA sequencing and bioinformatic analysis, a compliant report was issued.

\section{Statistical analysis}

SPSS 25 was used for data processing and analysis. The continuous variables were expressed as median and quartile, while categorial variables were expressed in quantity and percentage. Due to small amount of data collected, non-parametric test was used for the comparison of continuous variables while Chi-square test was used for the comparison of categorical variables between two groups. Multivariate Cox proportional hazard regression model [Method = Forward stepwise (Conditional LR)] was used to identify an independent prognostic factor. Kaplan-Meier method was used for survival analysis between two groups. $P<0.05$ was considered statistically significant.

\section{Results}




\section{Patient demographic characteristics}

A total of 53 patients were enrolled according to the criteria (Fig. 1), who had various complications, such as hypertension or diabetes mellitus. The majority were male and the median age was 68 years old. The most frequent detected virus was herpes simplex virus 1, followed by Epstein-Barr virus and cytomegalovirus ( Table 1 ). In total, 21 patients with virus nucleic acid detected in BALF made up the virus-detected group, 32 patients with virus nucleic acid undetected in BALF made up the virus-undetected group. 
Table 1

Demographic characteristics of the enrolled patients and the distribution of viruses detected in BALF 53 enrolled patients in total

Age

Gender

Male

Female

Medical history

Hypertension

Diabetes mellitus

Chronic respiratory dysfunction

Chronic heart failure

Chronic liver dysfunction

Chronic kidney dysfunction

Hematological disease

Solid organ tumor

Autoimmune disease

Hematopoietic stem cell transplantation

Solid organ transplantation

Numbers of virus strains detected in BALF

Herpes Simplex Virus 1

Herpes Simplex Virus 2

Varicella-Zoster Virus

Epstein-Barr Virus

Cytomegalovirus

Human Herpes Virus 6

Human Herpes Virus 7
$68(47.5,72)$

$40(75.5 \%)$

$13(24.5 \%)$

$23(43.4 \%)$

$11(20.8 \%)$

8 (15.1\%)

4 (7.5\%)

4 (7.5\%)

3 (5.7\%)

$3(5.7 \%)$

4 (7.5\%)

7 (13.2\%)

2 (3.8\%)

1 (1.9\%)

$9(17.0 \%)$

2 (3.8\%)

0 (0\%)

8 (15.1\%)

8 (15.1\%)

1 (1.9\%)

$3(5.7 \%)$

*Other viruses included 2 strains of adenovirus, one strain of polyomavirus, one strain of rhinovirus. Abbr. BALF, bronchial alveolar lavage fluid. 


\section{3 enrolled patients in total}

Other viruses*

$4(7.5 \%)$

*Other viruses included 2 strains of adenovirus, one strain of polyomavirus, one strain of rhinovirus.

Abbr. BALF, bronchial alveolar lavage fluid.

\section{Comparison between virus-detected group and virus- undetected group}

There were no differences between the virus-detected group and the virus-undetected group in age, gender and medical history. The two groups were comparable ( Table 2 ).

Table 2

Comparison of the demographic characteristics between virus-detected group and virus-undetected group

\begin{tabular}{|c|c|c|c|}
\hline & $\begin{array}{l}\text { virus-detected group }(\mathrm{N}= \\
21)\end{array}$ & $\begin{array}{l}\text { virus-undetected group }(\mathrm{N}= \\
\text { 32) }\end{array}$ & $\begin{array}{l}\mathrm{p} \\
\text { value }\end{array}$ \\
\hline Age & $68(63,74)$ & $64(46.3,71.8)$ & 0.244 \\
\hline Gender & & & 0.579 \\
\hline Male & $15(71.4 \%)$ & $25(78.1 \%)$ & \\
\hline Female & $6(28.6 \%)$ & $7(21.9 \%)$ & \\
\hline \multicolumn{4}{|l|}{ Medical history } \\
\hline Hypertension & $8(38.1 \%)$ & $15(46.9 \%)$ & 0.528 \\
\hline Diabetes mellitus & $3(14.3 \%)$ & $8(25.0 \%)$ & 0.552 \\
\hline $\begin{array}{l}\text { Chronic respiratory } \\
\text { dysfunction }\end{array}$ & $1(4.8 \%)$ & $7(21.9 \%)$ & 0.190 \\
\hline Chronic heart failure & $2(9.5 \%)$ & $2(6.3 \%)$ & 1.000 \\
\hline Chronic liver dysfunction & $1(4.8 \%)$ & $3(9.4 \%)$ & 0.928 \\
\hline Chronic kidney disfunction & $2(9.5 \%)$ & $1(3.1 \%)$ & 0.705 \\
\hline $\begin{array}{l}\text { Immunocompromised } \\
\text { status }^{\wedge}\end{array}$ & $8(38.1 \%)$ & $7(21.9 \%)$ & 0.200 \\
\hline \multicolumn{4}{|c|}{$\begin{array}{l}\text { Almmunocompromised status defined as patients undergoing solid organ transplantation, } \\
\text { hematopoietic stem cell transplantation, receiving corticosteroids (daily doses } \geq 20 \mathrm{mg} \text { prednisolone } \\
\text { or analogue for more than } 14 \text { days) or cytotoxic drugs, radiotherapy or chemotherapy treated for } \\
\text { cancer and etc }\end{array}$} \\
\hline \multicolumn{4}{|c|}{$P>0.05$, no statistical difference } \\
\hline
\end{tabular}


The virus-detected group had higher APACHE II scores [ $16(14,20.5)$ vs $13(9.25,16.75), P=0.006$ ] and higher total bilirubin concentration [ $18.1(14.9,25.5)$ vs $12.25(9.08,18.93), P=0.033$ ] compared to virus-undetected group. Other indices had no significant difference between two groups ( Table 3 ). There were both 6 participants with missing data for $\mathrm{CD}_{4} \%, \mathrm{CD}_{8} \%$ and $\mathrm{CD}_{4} / \mathrm{CD}_{8}$ ratio in each group. All other variables were completed. 
Table 3

Comparison of the relevant clinical indices between the virus-detected group and the virus-undetected group at the day of ICU admission

\begin{tabular}{|c|c|c|c|}
\hline & virus-detected group $(\mathrm{N}=21)$ & virus-undetected group $(\mathrm{N}=32)$ & $\mathrm{p}$ value \\
\hline APACHE II score & $16(14,20.5)$ & $13(9.3,16.8)$ & $0.006^{\star}$ \\
\hline SOFA score & $8(4.5,9.5)$ & $6(3.0,7.0)$ & 0.128 \\
\hline WBC $\left(X 10^{9} / \mathrm{L}\right)$ & $9.33(5.48,18.45)$ & $9.79(4.99,12.92)$ & 0.507 \\
\hline $\mathrm{CRP}(\mathrm{mg} / \mathrm{L})$ & $152.7(91.1,329.6)$ & $115.0(62.3,195.5)$ & 0.136 \\
\hline IL-6 (pg/ml) & $80(30,730)$ & $65(17,335)$ & 0.347 \\
\hline РCT (ng/ml) & $2.93(0.71,6.12)$ & $0.44(0.19,1.36)$ & 0.054 \\
\hline $\mathrm{G}$ test $(\mathrm{pg} / \mathrm{ml})$ & $306.1(64.9,2114.4)$ & $201.1(91.1,878.1)$ & 0.813 \\
\hline $\mathrm{CD}_{4} \%$ & $37.1(24.5,50.7)$ & $35.9(25.5,48.8)$ & 0.645 \\
\hline $\mathrm{CD}_{8} \%$ & $22.2(18.3,30.0)$ & $17.0(13.4,22.7)$ & 0.086 \\
\hline $\mathrm{CD}_{4} / \mathrm{CD}_{8}$ ratio & $1.56(0.96,2.03)$ & $1.74(1.09,3.09)$ & 0.267 \\
\hline $\operatorname{ALT}(\mathrm{U} / \mathrm{L})$ & $42(30,64)$ & $36(24,57)$ & 0.335 \\
\hline $\operatorname{ALB}(g / L)$ & $29.7(23.4,32.4)$ & $31.2(25.8,34.4)$ & 0.112 \\
\hline TB (umol/L) & $18.1(14.9,25.5)$ & $12.3(9.1,18.9)$ & $0.033^{*}$ \\
\hline Scr (umol/L) & $80(65,156)$ & $79(57,140)$ & 0.501 \\
\hline PT (s) & $13.1(12.4,15.2)$ & $13.0(11.7,14.5)$ & 0.317 \\
\hline $\operatorname{PLT}\left(X 10^{9} / \mathrm{L}\right)$ & $133(95,195)$ & $177(121,252)$ & 0.079 \\
\hline $\mathrm{cTnl}(\mathrm{ng} / \mathrm{ml})$ & $0.09(0.04,0.24)$ & $0.05(0.01,0.13)$ & 0.088 \\
\hline \multicolumn{4}{|c|}{$\begin{array}{l}\text { APCHE II, Acute Physiology and Chronic Health Evaluation II score. SOFA, Sequential Organ Failure } \\
\text { Assessment. WBC, leukocytes. CRP, C-reactive protein. IL-6, interleukin-6, PCT, procalcitonin. G-test, B- } \\
\text { (1,3)-D glucan. ALT, alanine transaminase. ALB albumin. TB, total bilirubin. Scr, serum creatinine. PT, } \\
\text { prothrombin time. PLT, platelet. cTnl, troponin. }\end{array}$} \\
\hline \multicolumn{4}{|c|}{$P>0.05$, no statistical difference } \\
\hline The two groups & statistically difference in APAC & II score and TB value $(P<0.05)$ & \\
\hline
\end{tabular}

The mortality rate ( $57.14 \%$ vs $25.00 \%, P=0.018$ ), tracheotomy rate ( $61.90 \%$ vs $34.38 \%, P=0.049$ ), RBC transfusion rate ( $80.95 \%$ vs $31.25 \%, P<0.001)$, Plasma transfusion rate $(71.43 \%$ vs $31.25 \%, P=0.004)$, Platelet transfusion rate $(38.10 \%$ vs $3.13 \%, P=0.003)$ were significantly higher in virus-detected group compared to virus-undetected group, and the virus-detected group had longer MV supporting time [ $504 \mathrm{~h}$ 
$(240,1043)$ vs $247.5 \mathrm{~h}(123.75,528), \mathrm{P}=0.012$ ]. Other parameters such as HLOS, ICULOS, hemodialysis rate had no significant difference between two group. Its seemed that patients with virus detected in BALF was prone to a poorer prognosis and patients needed more clinical resources in virusdetected group ( Table 4 ).

Table 4

Comparisons of the outcome and measured parameters between two groups

\begin{tabular}{|c|c|c|c|}
\hline & $\begin{array}{l}\text { virus-detected group }(\mathrm{N}= \\
21)\end{array}$ & $\begin{array}{l}\text { virus-undetected group }(\mathrm{N}= \\
32)\end{array}$ & p value \\
\hline Mortality\#, n (\%) & $12(57.1 \%)$ & $8(25.0 \%)$ & $0.018^{*}$ \\
\hline HLOS (d) & $29(13.3,51.8)$ & $21(12.5,35.3)$ & 0.313 \\
\hline ICULOS(d) & $29(10.8,49.0)$ & $14.8(11.1,33.5)$ & 0.326 \\
\hline MV Support Time ( h ) & $504(240,1043)$ & $248(124,528)$ & $0.012^{\star}$ \\
\hline Tracheotomy, n (\%) & $13(61.9 \%)$ & $11(34.4 \%)$ & $0.049 *$ \\
\hline Hemodialysis, n (\%) & $8(38.1 \%)$ & $4(12.5 \%)$ & 0.065 \\
\hline RBC transfusion, n (\%) & $17(81.0 \%)$ & $10(31.3 \%)$ & $<0.001$ * \\
\hline $\begin{array}{l}\text { Plasma transfusion, } \mathrm{n} \\
(\%)\end{array}$ & $15(71.4 \%)$ & $10(31.3 \%)$ & $0.004^{*}$ \\
\hline $\begin{array}{l}\text { Platelet transfusion, } \mathrm{n} \\
(\%)\end{array}$ & $8(38.1 \%)$ & $1(3.1 \%)$ & $0.003^{*}$ \\
\hline \multicolumn{4}{|c|}{ \#mortality: means patients died in ICU, or was dying when the client required being discharged } \\
\hline \multicolumn{4}{|c|}{$\begin{array}{l}\text { Abbr. HLOS, hospital length of stay. ICULOS, ICU length of stay. MV, mechanical ventilation, RBC, red } \\
\text { blood cell }\end{array}$} \\
\hline \multicolumn{4}{|c|}{$P>0.05$, no statistical difference } \\
\hline $\begin{array}{l}\text { The two groups had st } \\
\text { and MV support time ( }\end{array}$ & $\begin{array}{l}\text { ally difference in mortali } \\
\text { 5) }\end{array}$ & tracheotomy rate, blood tra & ion rate \\
\hline
\end{tabular}

Virus-detected was found to be an independent prognostic factor for ICU survival and Hospital survival time by Cox regression model, the relative hazard HR was 2.865 and 2.787 respectively (Table 5-6). 
Table 5

multivariate analysis by Cox regression model for ICU survival time

\begin{tabular}{|c|c|c|c|c|c|c|}
\hline & B & SE & wald & sig. & $\operatorname{Exp}(\mathrm{B})$ & $\mathrm{Cl}(95 \%)$ \\
\hline Virus detected & 1.053 & 0.457 & 5.304 & $0.021^{*}$ & 2.865 & $1.17 \sim 7.019$ \\
\hline APACHE II score & & & & 0.629 & & \\
\hline Total bilirubin concentration & & & & 0.152 & & \\
\hline
\end{tabular}

Table 6

Multivariate analysis by Cox regression model for hospital survival time

\begin{tabular}{|lllllll|}
\hline Factor & B & SE & wald & sig. & Exp (B) & Cl (95\%) \\
\hline Virus detected & 1.025 & 0.457 & 5.031 & $0.025^{*}$ & 2.787 & $1.138 \sim 6.823$ \\
APACHE II score & & & & 0.735 & & \\
\hline Total bilirubin concentration & & & 0.9 & \\
\hline $\begin{array}{l}\text { Virus-detected was found to be an independent prognostic factor for hospital survival by Cox } \\
\text { regression model, the relative hazard HR was 2.787 }\end{array}$ \\
$\lambda$
\end{tabular}

Abbr. ICU, intensive care unit; BALF, bronchial alveolar lavage fluid; AECOPD, acute exacerbation of chronic obstructive pulmonary diseases; CAP, community-acquired pneumonia

Fig 2. 28d ICU survival functions

Fig 3. 28d hospital survival functions

ICU survival functions showed that virus-undetected group had significantly longer ICU survival time than virus-detected group, which shared similarity in hospital survival functions ( Fig. 2 - Fig. 3 ).

\section{Discussion}

The detection rate for virus by traditional methods is extremely low. Since the advent of molecular diagnostic technologies such as PCR, the ability of diagnosing respiratory virus have been improved greatly. Next generation sequencing has better diagnostic performance on viral infection than traditional methods which mainly consist of isolation and identification, serology tests, and PCR which targets only a limited panel of specific viruses. mNGS technology can unbiasedly sequence all the DNA fragments and detect all pathogens in a sample in one time[9]. Many researches had confirmed that diagnostic efficiency of mNGS is superior to that of traditional methods. The pathogenic information obtained by mNGS could also help guiding the usage of clinical antibiotic and antiviral drugs, including initiation, deescalation, withdrawal of the drugs[10,11]. So, in this study, we chose the versatile mNGS to detect 
whether there were virus nucleic acid fragments in BALF instead of large amounts of conventional tests, avoiding missed diagnosis.

HSV can commonly be detected in BALF. The most frequent detected virus in our study was exact the HSV1. It's still unclear of the clinical significance of HSV detection in lower tract since the relationship between HSV detection and mortality in clinic were inconsistent in different studies[12]. At present, it was uncertain that HSV detected in lower respiratory tract of critically ill patients were related to poor prognosis, or it was just an epiphenomenon associated with disease severity and immune paralysis[13].

German researchers discovered that HSV-positive patients had longer HLOS and ICULOS compared to HSV-negative patients, there were no significant difference in ICU mortality rate or hospital mortality rate between two groups[14]. In our study, we found virus-positive patients had higher mortality rate and tracheotomy rate. Time required for ventilator support was longer in virus-detected group. The proportion of patients in virus-detected group who needed blood transfusion was also higher. It seemed that virus in BALF was not merely an innocent bystander, it did influence the patient to some extent.

Theoretically, viral infection could stimulate tremendous cytokine reactions, causing disorders in immune system. This kind of cytokine storm could also damage endothelial cells, trigger coagulation disorders, change microvascular permeability, induce tissue edema or even shock[1]. But patients in virus-detected group had higher APACHE II scores and TB value. It was hard to say that higher mortality rate was just determined by viral infection. We put "APACHE II scores ", "TB value" and "virus-detected" together into a Cox regression model and found that only "virus detected in BALF" had an effect on patient ICU survival time and hospital survival time. Virus-detected was supposed to be an independent risk factor for mortality

It is still uncertain about the influence of virus nucleic acid detected in critically ill patients with LRTI on the whole clinic procedure. To our knowledge, this was the first research discussing the prognosis of lower respiratory tract infected patients with virus detected in BALF by using mNGS. Samples used in previous research on correlation of virus and prognosis were mostly throat swabs and sputum, BALF was seldom used. So our results were relatively more convincing.

There were some limitations in our study. It was a just single-center, retrospective, observational study. The sample size was relatively small, it might lead to bias when generalized to a broader condition. Because of economic and technological reasons, the mNGS performed in this study were mainly aimed at DNA virus, instead of RNA virus. So common RNA virus such as influenza virus or respiratory syncytial virus was not shown in the reports, which could caused the deviation. Virus nucleic acid detected positive didn't mean virus infection. As long as there were virus DNA fragments in BALF, it could be detected positive no matter whether the virus was alive or not. Inapparent infection couldn't be distinguished from dominant infection. False positive results could easily appear because contamination might exit during sample collection, transportation, or in test procedure. Last but not least, as the limited laboratory conditions in our hospital, the results couldn't be verified by the PCR method for each patient. More largescale, multi-center, randomized, prospective researches on this topic are needed. 


\section{Conclusion}

In a conclusion, patients with virus detected in BALF might relate to a poor prognosis and require more clinical resources. The detection of virus was a high-risk factor of death for LRTI patients

Declarations

\section{Abbreviations}

\section{LRTI}

lower respiratory tract infection

\section{BALF}

bronchial alveolar lavage fluid

CAP

community acquired pneumonia

ICU

Intensive Care Unit

PCR

polymerase chain reaction

HLOS

hospital length of stay

ICULOS

ICU length of stay

NGS

next-generation sequencing

mNGS

metagenomic next-generation sequencing

MV

mechanical ventilation

RBC

red blood cell

APACHE II

Acute Physiology and Chronic Health Evaluation II score

SOFA

Sequential Organ Failure Assessment

\section{Declarations}

\section{Ethical approval and consent to participate}


The study was approved by the Ethics Committee of Shanghai General Hospital, Shanghai Jiao Tong University School of Medicine, China. Due to the retrospective nature of the study, informed consent was waived

\section{Availability of data and materials}

The datasets used and analyzed during the current study are available in supplementary material.

\section{Competing interests}

All the authors declared that there had no competing interest to this work.

\section{Consent for publication}

All the authors agreed to publish the study.

\section{Funding}

This project was supported by a grant from Shanghai science and technology committee scientific and technological support project ( No: 18411950602 ) and a grant from Clinical Research Innovation Plan of Shanghai General Hospital ( CTCCR-2016B01).

\section{Authors' contributions}

All the authors contributed equally in this work and approved the final manuscript.

\section{Acknowledgements}

We thank all the staff member for their invaluable efforts to this study.

\section{References}

1. Cantan B, Luyt CE, Martin-Loeches I. Influenza Infections and Emergent Viral Infections in Intensive Care Unit. Semin Respir Crit Care Med. 2019;40(4):488-97.

2. Jain S, Self WH, Wunderink RG, et al. Community-Acquired Pneumonia Requiring Hospitalization among U.S. Adults. N Engl J Med. 2015;373(5):415-27.

3. Jain S, Williams DJ, Arnold SR, et al. Community-acquired pneumonia requiring hospitalization among U.S. children. N Engl J Med. 2015;372(9):835-45.

4. leven $\mathrm{M}$, Coenen $\mathrm{S}$, Loens $\mathrm{K}$, et al. Aetiology of lower respiratory tract infection in adults in primary care: a prospective study in 11 European countries. Clinical microbiology infection: the official 
publication of the European Society of Clinical Microbiology Infectious Diseases. 2018;24(11):115863.

5. Blauwkamp TA, Thair S, Rosen MJ, et al. Analytical and clinical validation of a microbial cell-free DNA sequencing test for infectious disease. Nat Microbiol. 2019;4(4):663-74.

6. Chiu CY, Miller SA. Clinical metagenomics. Nat Rev Genet. 2019;20(6):341-55.

7. Vergara $\mathrm{A}$, Cilloniz $\mathrm{C}$, Luque $\mathrm{N}$, et al. Detection of human cytomegalovirus in bronchoalveolar lavage of intensive care unit patients. Eur Respir J. 2018;51(2).

8. Burgener EB, Waggoner J, Pinsky BA, et al. Clinical characteristics and outcomes of pediatric patients with CMV DNA detection in bronchoalveolar lavage fluid. Pediatr Pulmonol. 2017;52(1):112-8.

9. Kawada J, Okuno Y, Torii Y, et al. Identification of Viruses in Cases of Pediatric Acute Encephalitis and Encephalopathy Using Next-Generation Sequencing. Sci Rep. 2016;6:33452.

10. Miao Q, Ma Y, Wang Q, et al. Microbiological Diagnostic Performance of Metagenomic Nextgeneration Sequencing When Applied to Clinical Practice. Clinical infectious diseases: an official publication of the Infectious Diseases Society of America. 2018;67(suppl_2):231-S40.

11. Wilson MR, Sample HA, Zorn KC, et al. Clinical Metagenomic Sequencing for Diagnosis of Meningitis and Encephalitis. N Engl J Med. 2019;380(24):2327-40.

12. Simoons-Smit AM, Kraan EM, Beishuizen A, et al. Herpes simplex virus type 1 and respiratory disease in critically-ill patients: Real pathogen or innocent bystander? Clinical microbiology and infection: the official publication of the European Society of Clinical Microbiology and Infectious Diseases. 2006;12(11):1050-9.

13. Scheithauer $S$, Manemann AK, Kruger $S$, et al. Impact of herpes simplex virus detection in respiratory specimens of patients with suspected viral pneumonia. Infection. 2010;38(5):401-5.

14. Saugel B, Jakobus J, Huber W, et al. Herpes simplex virus in bronchoalveolar lavage fluid of medical intensive care unit patients: Association with lung injury and outcome. J Crit Care. 2016;32:138-44.

\section{Highlights}

- Patients with virus detected in bronchial alveolar lavage fluid were prone to a worse prognosis

- Patients with virus detected in bronchial alveolar lavage fluid needed more clinical resources

- Virus-detected might be an independent prognostic factor for ICU survival and Hospital survival time

\section{Tables}


Table 1. Demographic characteristics of the enrolled patients and the distribution of viruses detected in BALF

\begin{tabular}{|c|c|}
\hline & 53 enrolled patients in total \\
\hline Age & $68(47.5,72)$ \\
\hline \multicolumn{2}{|l|}{ Gender } \\
\hline Male & $40(75.5 \%)$ \\
\hline Female & $13(24.5 \%)$ \\
\hline \multicolumn{2}{|l|}{ Medical history } \\
\hline Hypertension & $23(43.4 \%)$ \\
\hline Diabetes mellitus & $11(20.8 \%)$ \\
\hline Chronic respiratory dysfunction & $8(15.1 \%)$ \\
\hline Chronic heart failure & $4(7.5 \%)$ \\
\hline Chronic liver dysfunction & $4(7.5 \%)$ \\
\hline Chronic kidney dysfunction & $3(5.7 \%)$ \\
\hline Hematological disease & $3(5.7 \%)$ \\
\hline Solid organ tumor & $4(7.5 \%)$ \\
\hline Autoimmune disease & $7(13.2 \%)$ \\
\hline Hematopoietic stem cell transplantation & $2(3.8 \%)$ \\
\hline Solid organ transplantation & $1(1.9 \%)$ \\
\hline \multicolumn{2}{|l|}{ Numbers of virus strains detected in BALF } \\
\hline Herpes Simplex Virus 1 & $9(17.0 \%)$ \\
\hline Herpes Simplex Virus 2 & $2(3.8 \%)$ \\
\hline Varicella-Zoster Virus & $0(0 \%)$ \\
\hline Epstein-Barr Virus & $8(15.1 \%)$ \\
\hline Cytomegalovirus & $8(15.1 \%)$ \\
\hline Human Herpes Virus 6 & $1(1.9 \%)$ \\
\hline Human Herpes Virus 7 & $3(5.7 \%)$ \\
\hline Other viruses* & $4(7.5 \%)$ \\
\hline
\end{tabular}

*Other viruses included 2 strains of adenovirus, one strain of polyomavirus, one strain of rhinovirus.

Abbr. BALF, bronchial alveolar lavage fluid.

Table 2. Comparison of the demographic characteristics between virus-detected group and virus-undetected group

\begin{tabular}{llll}
\hline & virus-detected group $(\mathrm{N}=21)$ & virus-undetected group $(\mathrm{N}=32)$ & $\mathrm{p}$ value \\
\hline Age & $68(63,74)$ & $64(46.3,71.8)$ & 0.244 \\
\hline Gender & & & 0.579 \\
\hline Male & $15(71.4 \%)$ & $25(78.1 \%)$ & $7(21.9 \%)$ \\
\hline Female & $6(28.6 \%)$ & & 0.528 \\
\hline Medical history & & $15 \square 46.9 \% \square$ & 0.552 \\
\hline Hypertension & $8 \square 38.1 \% \square$ & $8 \square 25.0 \% \square$ & 0.190 \\
\hline Diabetes mellitus & $3 \square 14.3 \% \square$ & $7 \square 21.9 \% \square$ & 1.000 \\
\hline Chronic respiratory dysfunction & $1 \square 4.8 \% \square$ & $2 \square 6.3 \% \square$ & 0.928 \\
\hline Chronic heart failure & $2 \square 9.5 \% \square$ & $3 \square 9.4 \% \square$ & 0.705 \\
\hline Chronic liver dysfunction & $1 \square 4.8 \% \square$ & $1 \square 3.1 \% \square$ & 0.200
\end{tabular}

^Immunocompromised status defined as patients undergoing solid organ transplantation, hematopoietic stem cell transplantation, receiving corticosteroids (daily doses $\geq 20 \mathrm{mg}$ prednisolone or analogue for more than 14 days) or cytotoxic drugs, radiotherapy or chemotherapy treated for cancer and etc

$\mathrm{P}>0.05$, no statistical difference 
Table 3. Comparison of the relevant clinical indices between the virus-detected group and the virus-undetected group at the day of ICU zdmission

\begin{tabular}{|c|c|c|c|}
\hline & virus-detected group $(\mathrm{N}=21)$ & virus-undetected group $(\mathrm{N}=32)$ & $\mathrm{p}$ value \\
\hline APACHE II score & $16 \square 14 \square 20.5 \square$ & $13 \square 9.3 \square 16.8 \square$ & $0.006^{*}$ \\
\hline ¡OFA score & $8 \square 4.5 \square 9.5 \square$ & $6 \square 3.0 \square 7.0 \square$ & 0.128 \\
\hline WBC $\left(\right.$ X $\left.10^{9} / L\right)$ & $9.33 \square 5.48 \square 18.45 \square$ & $9.79 \square 4.99 \square 12.92 \square$ & 0.507 \\
\hline こRP $(\mathrm{mg} / \mathrm{L})$ & $152.7 \square 91.1 \square 329.6 \square$ & $115.0 \square 62.3 \llbracket 195.5 \square$ & 0.136 \\
\hline$[\mathrm{L}-6(\mathrm{pg} / \mathrm{ml})$ & $80 \square 30 \square 730 \square$ & $65 \square 17 \square 335 \square$ & 0.347 \\
\hline PCT (ng/ml) & $2.93 \square 0.71 \square 6.12 \square$ & $0.44 \square 0.19 \square 1.36 \square$ & 0.054 \\
\hline 3 test $(\mathrm{pg} / \mathrm{ml})$ & $306.1 \square 64.9 \square 2114.4 \square$ & $201.1 \square 91.1 \square 878.1 \square$ & 0.813 \\
\hline $2 \mathrm{D}_{4} \%$ & $37.1 \square 24.5 \square 50.7 \square$ & $35.9 \square 25.5 \square 48.8 \square$ & 0.645 \\
\hline $2 \mathrm{D}_{8} \%$ & $22.2 \square 18.3 \square 30.0 \square$ & $17.0 \square 13.4 \square 22.7 \square$ & 0.086 \\
\hline $\mathrm{CD}_{4} / \mathrm{CD}_{8}$ ratio & $1.56 \square 0.96 \square 2.03 \square$ & $1.74 \square 1.09 \square 3.09 \square$ & 0.267 \\
\hline $\mathrm{ALT}(\mathrm{U} / \mathrm{L})$ & $42 \square 30 \square 64 \square$ & $36 \square 24 \square 57 \square$ & 0.335 \\
\hline $\mathrm{ALB}(\mathrm{g} / \mathrm{L})$ & $29.7 \square 23.4 \square 32.4 \square$ & $31.2 \square 25.8 \square 34.4 \square$ & 0.112 \\
\hline ГВ (umol/L) & $18.1 \square 14.9 \llbracket 25.5 \square$ & $12.3 \square 9.1 \square 18.9 \square$ & $0.033^{*}$ \\
\hline 亏̇cr (umol/L) & $80 \square 65 \square 156 \square$ & $79 \square 57 \square 140 \square$ & 0.501 \\
\hline PT (s) & $13.1 \square 12.4 \square 15.2 \square$ & $13.0 \square 11.7 \square 14.5 \square$ & 0.317 \\
\hline PLT (X 109/L) & $133 \llbracket 95 \square 195 \square$ & $177 \square 121 \square 252 \square$ & 0.079 \\
\hline ¿TnI (ng/ml) & $0.09 \square 0.04 \square 0.24 \square$ & $0.05 \square 0.01 \square 0.13 \square$ & 0.088 \\
\hline
\end{tabular}

APCHE II, Acute Physiology and Chronic Health Evaluation II score. SOFA, Sequential Organ Failure Assessment. WBC, leukocytes. CRP, Creactive protein. IL-6, interleukin-6, PCT, procalcitonin. G-test, ß-(1,3)-D glucan. ALT, alanine transaminase. ALB albumin. TB, total bilirubin. Scr, serum creatinine. PT, prothrombin time. PLT, platelet. cTnI, troponin.

$\mathrm{P}>0.05$, no statistical difference

The two groups had statistically difference in APACHE II score and TB value $(\mathrm{P}<0.05)$

Table 4. Comparisons of the outcome and measured parameters between two groups

\begin{tabular}{llll} 
& virus-detected group $(\mathrm{N}=21)$ & virus-undetected group $(\mathrm{N}=32)$ & p value \\
\hline Mortality\#, n (\%) & $12(57.1 \%)$ & $8(25.0 \%)$ & $0.018^{*}$ \\
\hline HLOS (d) & $29(13.3,51.8)$ & $21(12.5,35.3)$ & 0.313 \\
\hline ICULOS(d) & $29(10.8,49.0)$ & $14.8(11.1,33.5)$ & 0.326 \\
\hline MV Support Time ( $)$ & $504(240,1043)$ & $248(124,528)$ & $0.012^{*}$ \\
\hline Tracheotomy, n (\%) & $13(61.9 \%)$ & $11(34.4 \%)$ & $0.049^{*}$ \\
\hline Hemodialysis, n (\%) & $8(38.1 \%)$ & $4(12.5 \%)$ & 0.065 \\
\hline RBC transfusion, $\mathrm{n}(\%)$ & $17(81.0 \%)$ & $10(31.3 \%)$ & $<0.001^{*}$ \\
\hline Plasma transfusion, $\mathrm{n}(\%)$ & $15(71.4 \%)$ & $10(31.3 \%)$ & $0.004^{*}$ \\
\hline Platelet transfusion, $\mathrm{n}(\%)$ & $8(38.1 \%)$ & $1(3.1 \%)$ & $0.003^{*}$
\end{tabular}

\#mortality: means patients died in ICU, or was dying when the client required being discharged

Abbr. HLOS, hospital length of stay. ICULOS, ICU length of stay. MV, mechanical ventilation, RBC, red blood cell

$\mathrm{P}>0.05$, no statistical difference

The two groups had statistically difference in mortality rate, tracheotomy rate, blood transfusion rate and MV support time $(\mathrm{P}<0.05)$ 
Table 5. multivariate analysis by Cox regression model for ICU survival time

\begin{tabular}{|c|c|c|c|c|c|c|c|}
\hline & $\mathrm{B}$ & $\mathrm{SE}$ & wald & sig. & $\operatorname{Exp}(\mathrm{B})$ & CI ( $95 \%)$ & \\
\hline Virus detected & 1.053 & 0.457 & 5.304 & $0.021 *$ & 2.865 & $1.17 \sim 7.019$ & \\
\hline APACHE II score & & & & 0.629 & & & \\
\hline Total bilirubin concentration & & & & 0.152 & & & l, the relative hazard $\mathrm{HR}$ w \\
\hline
\end{tabular}

Table 6 Multivariate analysis by Cox regression model for hospital survival time

\begin{tabular}{lllllll}
\hline Factor & B & SE & wald & sig. & Exp (B ) & CI (95\%) \\
\hline Virus detected & 1.025 & 0.457 & 5.031 & $0.025^{*}$ & 2.787 & $1.138 \sim 6.823$ \\
\hline APACHE II score & & \multicolumn{5}{c}{0.735} \\
Total bilirubin concentration & & \multicolumn{5}{c}{0.9}
\end{tabular}

Virus-detected was found to be an independent prognostic factor for hospital survival by Cox regression model, the relative hazard HR was 2.787

\section{Figures}




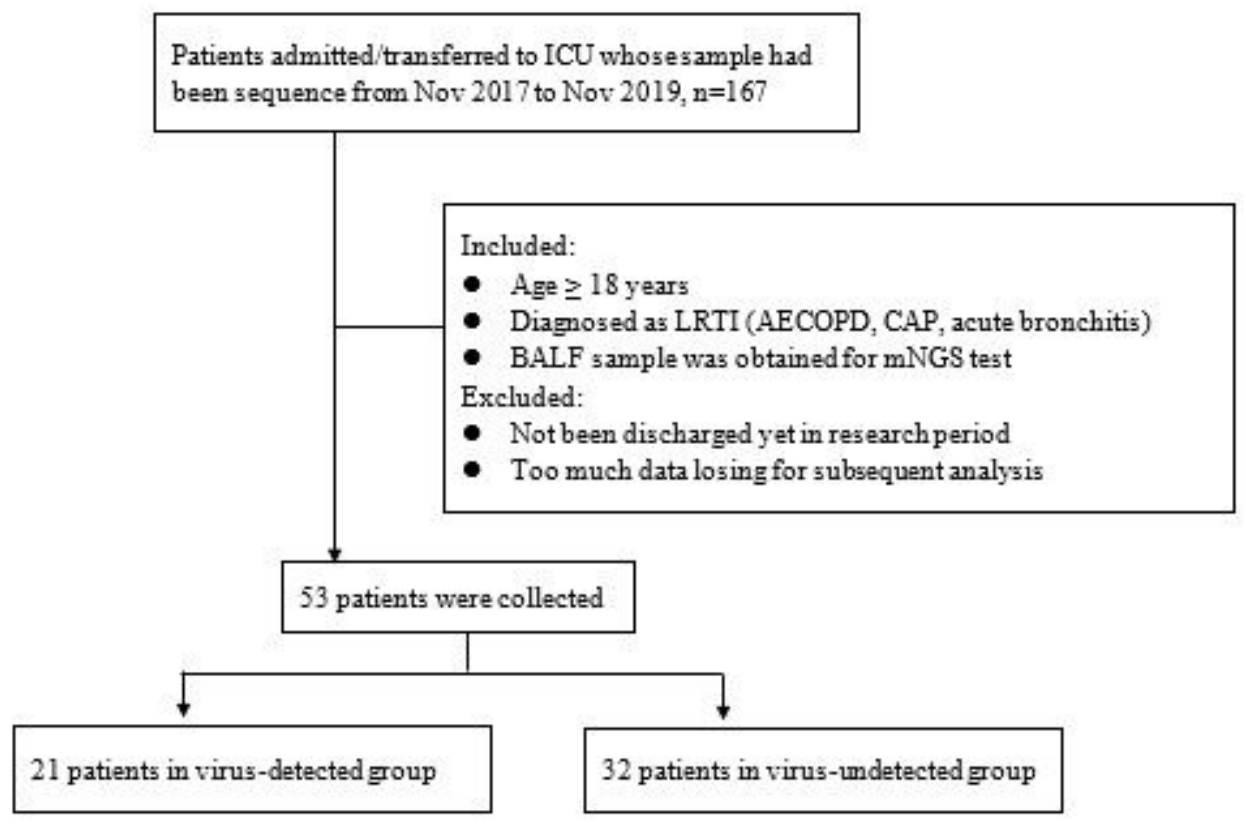

Abbr. ICU, intensive care unit; BALF, bronchial alveolar lavage fluid; AECOPD, acute

exacerbation of chronic obstructive pulmonary diseases; CAP, community-acquired pneumonia

\section{Figure 1}

Flowchart of patients selection

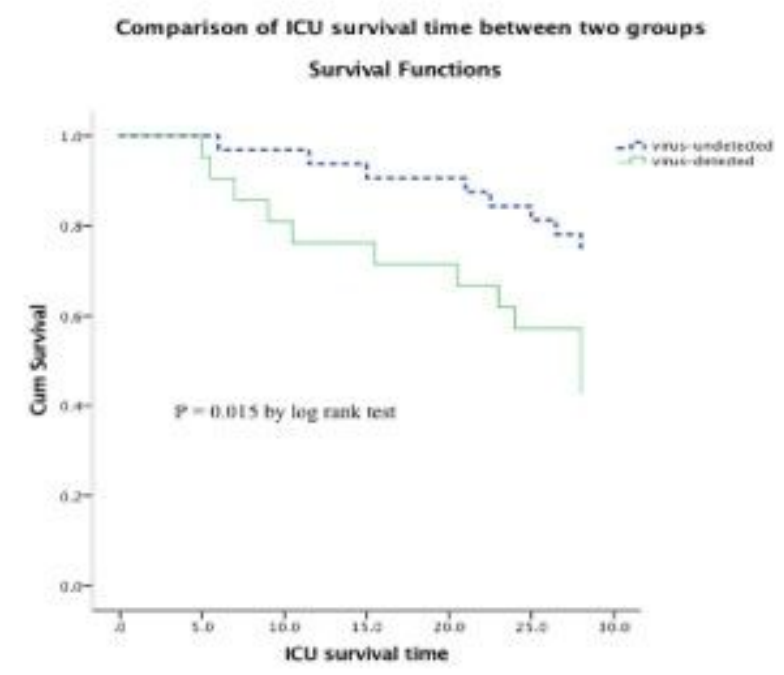


Figure 2

28d ICU survival functions

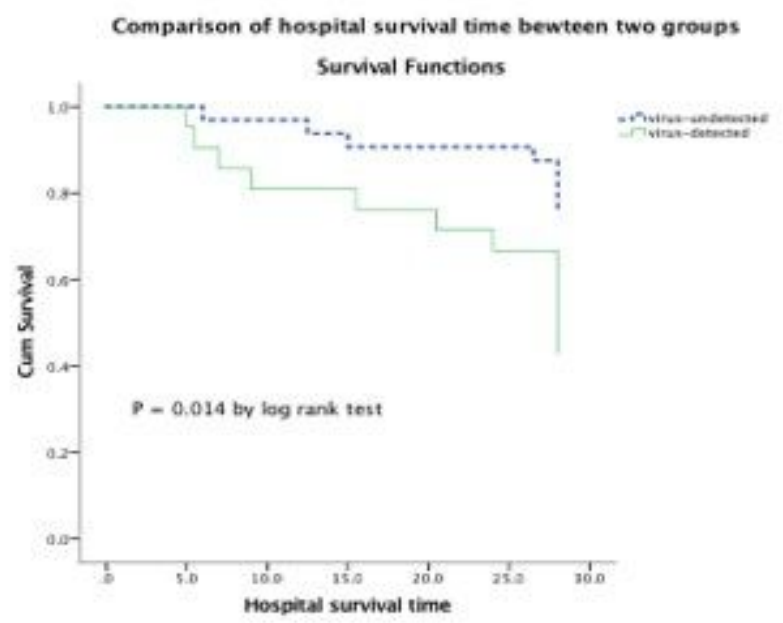

Figure 3

$28 d$ hospital survival functions

\section{Supplementary Files}

This is a list of supplementary files associated with this preprint. Click to download.

- originaldata.xlsx

- STROBEchecklistcohort.doc 